\title{
Protective effects of orange (Citrus sinensis L.) D cossmak peel aqueous extract and hesperidin on oxidative stress and peptic ulcer induced by alcohol in rat
}

Slimen Selmi ${ }^{*}$ Kais Rtibi, Dhekra Grami, Hichem Sebai and Lamjed Marzouki

\begin{abstract}
Background: Massive alcohol drinking can lead to gastric ulcer. In the present study we investigated the gastroprotective effect of Citrus sinensis peel aqueous extract (CSPE) and Hesperidin (H) in ethanol (EtOH) induced oxidative stress and peptic ulcer in rats.
\end{abstract}

Methods: Seventy adult male Wistar rats were divided into seven groups of 10 each: control, EtOH (4 g/kg b.w.), $\mathrm{EtOH}+$ various doses of CSPE (100, 200 and $400 \mathrm{mg} / \mathrm{kg}$, b.w.), EtOH + Hesperidin (50 mg/kg, p.o.) and EtOH + Omeprazole (OM, $20 \mathrm{mg} / \mathrm{kg}$, p.o.). Animals were perorally (p.o.) pre-treated with CSPE during 15 days and intoxicated with a single oral administration of EtOH (4 g/kg b.w.) during $2 \mathrm{~h}$. Gastric ulcer was induced in rats with a single dose of ethanol (EtOH). Ulcer index, gene expression of gastric cyclooxygenase-2 (COX-2), tumor necrosis factor alpha (TNF-a), malondialdhyde (MDA), hydrogen peroxide $\mathrm{H}_{2} \mathrm{O}_{2}$ and Thiol groups $(-\mathrm{SH})$ content in stomach and antioxidant enzymes superoxide dismutase (SOD), catalase (CAT) and gluthation peroxidise (GPX) were measured. Furthermore, histopathological examinations were performed.

Results: The results showed that ethanol induced gastric damage, improving oxidative stress markers level such as MDA (121 $\pm 4.45 \mathrm{nmol} / \mathrm{mg}$ proteins) and $\mathrm{H}_{2} \mathrm{O}_{2}(24.62 \pm 1.04 \mu \mathrm{mol} / \mathrm{mg}$ proteins), increased pro-inflammatory cytokine (TNF-a level), as well as the expression of COX-2 in the ethanol group. However, a significant depletion of enzymatic and non-enzymatic antioxidants were observed, such as, GPx (72\%), SOD (57.5\%), CAT (41.6\%) and -SH (50\%). The lesions were associated with severe histopathological damage. The both Citrus sinensis peel aqueous extract (CSPE) and hesperidin significantly protect against all gastric damages caused by ethanol administration in rats.

Conclusions: We propose that CSPE and hesperidin exhibit protective effects in EtOH-induced peptic ulcer in rat. This protection might be related in to part its antioxidant properties as well as its opposite effects on some studied intracellular mediators.

Keywords: Citrus sinensis peel, Hesperidin, Gastric ulcer, Oxidative stress markers, COX-2, TNF-a, Rat

\footnotetext{
* Correspondence: slimen.selmi@gmail.com

Higher Institute of Biotechnology of Beja, Laboratory Functional Physiology

and Bio-resources Valorisation, University of Jendouba, Avenue Habib

Bourguiba, BP, 382, 9000 Beja, Tunisia
}

(c) The Author(s). 2017 Open Access This article is distributed under the terms of the Creative Commons Attribution 4.0 International License (http://creativecommons.org/licenses/by/4.0/), which permits unrestricted use, distribution, and reproduction in any medium, provided you give appropriate credit to the original author(s) and the source, provide a link to the Creative Commons license, and indicate if changes were made. The Creative Commons Public Domain Dedication waiver (http://creativecommons.org/publicdomain/zero/1.0/) applies to the data made available in this article, unless otherwise stated. 


\section{Background}

Gastric ulcers affect annually approximately 4 million people in the globe $[1,2]$. This pathology is a heterogeneous disease of multifactorial etiology which can result from alcohol consumption, smoking, Helicobacter pylori infections, use of anti-inflammatory drugs (NSAIDs) [3]. This condition affects approximately $10-15 \%$ of the population in the world [4]. Gastric ulcers are typically caused by an imbalance between protective factors (blood flow, cell regeneration secretion, epithelial barrier and mucus secretion) and aggressive factors (reactive oxygen species [ROS] and acid-pepsin secretion) in the gastric mucosa [5]. The production of ROS plays a major role in the apparition and development of stomachal pathologies, such as gastric adenocarcinoma, peptic ulcerations, or gastritis [6]. In this respect, gastric mucosal layers represent a dynamic barrier in counteracting the effects of noxious agents through series of endogenous antioxidant defense systems. Indeed, this increase of oxidative damages is known to be related to the destructive factors-induced gastric mucosal damage [7, 8]. The mechanisms underlying the ethanol-induced gastric and duodenal injuries have not yet been fully elucidated.

Currently, the main pharmacological treatment for this disease is antisecretory drugs including, histamine type 2 receptor antagonists such as cimetidine and congeners, and irreversible proton pump inhibitors such as omeprazole, famotidine and congeners. Although effective, longterm treatment with these drugs is associated with several side effects and poor gastric healing, leading to ulcer recurrence [9].

The clinical importance of this pathology has led to the development of many pharmaceuticals and researches have already tested several natural compounds to prevent or treat gastric ulcers. Several naturally occurring antioxidant compounds were largely used to protect against gastric and duodenal diseases both in experimental and clinical situations. The plants and herbs are used to treat different diseases such as gastrointestinal illnesses, including peptic ulcers without side effects in ayurvedic medicinal system [10].

In the other hand, during fruit consumption's, large quantities of wastes accumulate, however these materials may have some constituents of great significance generate substantial quantities of phenolics-rich sub products, which could be valuable natural sources of polyphenols. Hesperidin, is one of the bioflavonoids which is greatly found in Citrus species and is one of the major active constituent of tangerine (Citrus reticulata) and sweet orange (Citrus sinensis) peel $[11,12]$. Many specific scientific efforts have demonstrated that dietary flavonoids have a variety of pharmacological properties, qy [13] and anti-ulcer [14] activities. In addition, the consumption of specific dietary flavonoids has been correlated with a reduced risk in the onset of some chronic and complex diseases, such as different types of cancer, asthma and cardiovascular disorders $[15,16]$. One of the most important pharmacological aspects of flavonoids is considered to be the antioxidant and free radical scavenging activities [17]. In this regard, many recent studies have demonstrated the benefit of the use of Citrus sinensis peel aqueous extract and hesperidin in the treatment of patients suffering from venous leg ulcer and/or haemorrhoids [18]. Interestingly, orange peel is an interesting source of phenolic compounds, and in particular flavonoids such as hesperidin. Furthermore, Orange peel is also the primary waste fraction in the production of orange juice, although it has been used as a source of hesperidin because of its high concentration within this material [19].

Accordingly, the present study was designed to evaluate the putative gastroprotective role of the aqueous extract of Citrus sinensis peel (CSPE) and hesperidin (15 days) against oxidative stress induced by acute ethanol exposure and the mechanism involved in such protection.

\section{Methods \\ Plant materials}

The fresh fruit peel of orange (Citrus sinensis L.) was collected from North Est Tunisia (Mornag, Ben Arous, Tunisia) in December 2014. The identity of the plants was confirmed and deposit at the herbarium of the Higher Institute of Biotechnology of Beja and recognized at Tunisian Gene Bank (GNB 000600017).

\section{Flavonoids extraction and isolation}

Flavonoid extraction and isolation was determined. Briefly, dried peel of orange (850 g) was exhaustively extracted with $80 \%$ aqueous methanol $(3 \times 4 \mathrm{~L})$ which was concentrated under vacuum to yield $225 \mathrm{~g}$ of a viscous greenish residue.

\section{Total phenolic content}

Total phenolic content was determined by the colorimetric Folin-Cieucalteu method [20]. Briefly, $500 \mu \mathrm{L}$ of the extract were added to $10 \mathrm{ml}$ of water and $0.5 \mathrm{ml}$ of Folin-Cieucalteu reagent. After $5 \mathrm{~min}, 8 \mathrm{ml}$ of $7.5 \%$ sodium carbonate solution were added. The reaction mixture was kept in the dark for $2 \mathrm{~h}$ and its optical density was measured at $765 \mathrm{~nm}$ using a UV-visible spectrophotometer (Beckman DU 640B). Gallic acid was applied as standard, and the results were expressed as $\mathrm{mg}$ of gallic acid equivalents per gram of dry weight (mg GAE/g DW).

\section{Total flavonoids determination}

Total flavonoid content was determined by the $\mathrm{AlCl}_{3}$ colorimetric method [21]. Briefly, $1 \mathrm{~mL}$ of the sample was mixed with $1 \mathrm{~mL}$ of $2 \%$ aluminium chloride 
solution. After incubation for $15 \mathrm{~min}$ at room temperature, the optical density of the reaction mixture was evaluated at $430 \mathrm{~nm}$. Quercetin was used as a citation standard and the total flavonoid content was expressed as $\mathrm{mg}$ of quercetin equivalent per gram of dry weight (mg QtE/g DW).

\section{Free radical-scavenging activity on $D P P H$}

The antioxidant capacity of MBSAE was performed using 2,2-diphenyl-1-picrylhydrazyl (DPPH) radical-scavenging activity as previously described by Grzegorczyk et al., [22] .

Briefly, various concentrations of CSPE (50, 100, 200, 400 , and $600 \mu \mathrm{g} / \mathrm{mL}$ ) were added to $1 \mathrm{~mL}$ of $0.1 \mathrm{mM}$ methanol solution of DPPH and incubated at $27{ }^{\circ} \mathrm{C}$ during $30 \mathrm{~min}$. The optical density of the sample was quantified at $517 \mathrm{~nm}$. DPPH radical-scavenging activity (RSA), expressed as a percentage, was estimated utilizing the following formula:

Quercetin was used as a reference molecule in the same concentration as the test extract.

$$
\left.\boldsymbol{R S A}(\%)=\left(\left(A_{D P P H}-A_{\text {control }}\right) / A_{D P P H}\right)\right) \times 100
$$

All the analyses were executed in triplicate. The efficacy concentration 50 (EC50) value was determined as the concentration (in $\mu \mathrm{g} / \mathrm{mL}$ ) of the compound required to scavenge $50 \%$ of the DPPH radical.

\section{Superoxide anion scavenging activity}

The superoxide anion $\left(\mathrm{O}^{*-}\right)$ scavenging activity was performed according to Marklund and Marklund [23]. Briefly, $0.2 \mathrm{ml}$ various concentrations of CSPE were added to $5.7 \mathrm{~mL}$ of $50 \mathrm{mM}$ Tris- $\mathrm{HCl}$ buffer ( $\mathrm{pH} \mathrm{8.2).}$ The mixture was incubated at $25{ }^{\circ} \mathrm{C}$ during $10 \mathrm{~min}$ and then added to $0.1 \mathrm{ml}$ of $6 \mathrm{Mm}$ pyrogallol (dissolved in $10 \mathrm{mmol} / \mathrm{L} \mathrm{HCl}$ ). The absorbance of the reaction mixture was determined at $320 \mathrm{~nm}$ and the superoxide anion scavenging activity (SASA) was calculated using the following formula

$$
\operatorname{SASA}(\%)=\left[1-\left(A_{1}-A_{2}\right) / A_{0}\right] \times 100
$$

$A_{0}$ is the autoxidation rate of pyrogallol for control (the change of the absorbance), $A_{1}$ is the oxidation rate of pyrogallol for samples, and $A_{2}$ is the absorbance of the sample blank.

\section{Antiulcerogenic activity of CSPE Animals and treatment}

Adult male Wistar rats (weighing 220-240 g; housed five per cage) were purchased from Pasteur Institute of Tunis and used in accordance with the local ethic committee of Tunis University for use and care of animals in accordance with the NIH recommendations. They were provided with food (standard pellet diet- Badr Utique-TN) and water ad libitum and maintained in animal house at controlled temperature $\left(22 \pm 2{ }^{\circ} \mathrm{C}\right)$ with $12 \mathrm{~h}$ light-dark cycle. Experimental protocols were approved with the guidelines of the Ethical Committee of Science Faculty of Tunis, Tunisia. The test was performed in compliance with the Commission Directive 2000/32/EC and the OECD Guideline 474.

The rats were divided into seven groups of 10 animals each. Group 1 and 2 were served as control and had bidistilled water $(5 \mathrm{~mL} / \mathrm{kg}$, b.w., p.o.). Groups 3,4 and 5 were pre-treated with various doses of CSPE (100, 200 and $400 \mathrm{mg} / \mathrm{kg}$, b.w., p.o.), while group 6 and group 7 were pre-treated respectively with omeprazole $(20 \mathrm{mg} / \mathrm{kg}$, b.w., p.o.) and Hesperidin (50 mg/kg, b.w., p.o.). The period of pretreatment was 15 days.

Animals were fasted for $24 \mathrm{~h}$ before the last administration of CSPE or reference molecules. After $2 \mathrm{~h}$, each animal, except those of groups 1 and 2, was intoxicated by acute administration of $\mathrm{EtOH}(4 \mathrm{~g} / \mathrm{kg}$, b.w., p.o.). Sixty min later, animals were sacrificed.

Blood was collected in heparinized tubes. After centrifugation at $3000 \mathrm{~g}$ during $15 \mathrm{~min}$, plasma was treated for PSA determination.

\section{Evaluation of gastric mucosal damage}

The stomach of each animal were removed and opened along its greater curvature. The tissues were gently rinsed in $\mathrm{NaCl} 0.9 \%$. Ulcer indexes were determined as the sum of the lengths of the whole gastric lesions (in $\mathrm{mm}^{2}$ ).

\section{Gastric tumor necrosis factor alpha (TNF-a) assay}

The TNF- $\alpha$ level was detected by an ELISA kit supplied by Quantikine, R\&D system (USA) according to the method of Maskos et al., [24].

\section{Real-time PCR}

The expression of COX-2 was determined by real time PCR according to the method of Walch and Morris [25]. Total RNA was isolated from gastric tissue and mRNA was purified using RNeasy Purification Reagent (Qiagen, Valencia, CA), reverse transcribed into cDNA, and amplified by PCR. The reaction mixture was subjected to 40 cycles of PCR amplification as follows: denaturation at $95{ }^{\circ} \mathrm{C}$ for $1 \mathrm{~min}$, annealing at $60{ }^{\circ} \mathrm{C}$ for $1 \mathrm{~min}$ and extension at $72{ }^{\circ} \mathrm{C}$ for $2 \mathrm{~min}$. Semi-quantitation was performed using gel documentation system (Quantity one, Germany). Primer sequences for amplification of COX-2 are:

\section{Forward: 5 -GCAAATCCTTGCTGTTCCAATC-3} Reverse: 5 -GGAGAAGGCTTCCCAGCTTTTG-3

And for $\beta$-actin as a house keeping gene we used the following primers: 
Forward 5 -GCC ATG TAC GTA GCC ATC CA-3 Reverse 5-GAA CCG CTC ATT GCC GAT AG -3.

\section{Histopathological analysis}

Immediately after sacrifice, small pieces of stomach and duodenum were harvested and washed with ice cold saline. Tissue fragments were then fixed in a $10 \%$ neutral buffered formalin solution, embedded in paraffin and used for histopathological examination. $5 \mu \mathrm{m}$ thick sections were cut, deparaffinized, hydrated and stained with hematoxylin and eosin (HE). The sections were examined in blind fashion for all treatments.

\section{Stomach mucosa preparation}

After the gastric lesions analyses, the stomach mucosa was rapidly excised and homogenized in phosphate buffer saline $\left(\mathrm{KH}_{2} \mathrm{PO}_{4} / \mathrm{K}_{2} \mathrm{HPO}_{4}, 50 \mathrm{mM}\right.$, pH 7.4) with Potter-Elvehjem homogenizer. After centrifugation at $10000 \mathrm{~g}$ for $10 \mathrm{~min}$ at $4{ }^{\circ} \mathrm{C}$, supernatants were used for biochemical determination of protein, free iron, $\mathrm{H}_{2} \mathrm{O}_{2}$, calcium, $\mathrm{SH}$ - groups, MDA and antioxidant enzyme activities.

\section{Lipid peroxidation measurement}

Lipid peroxidation was determined by MDA measurement according to the double heating method [26]. Briefly, aliquots from gastric mucosa homogenates were mixed with BHT-TCA solution containing 1\% BHT $(w / v)$ dissolved in 20\% TCA $(w / v)$ and centrifuged at $1000 \mathrm{~g}$ for 5 min at $4{ }^{\circ} \mathrm{C}$. Supernatant was blended with $0.5 \mathrm{~N} \mathrm{HCl}$ and $120 \mathrm{mM}$ TBA in $26 \mathrm{mM}$ Tris and then heated at $80{ }^{\circ} \mathrm{C}$ for $10 \mathrm{~min}$. After cooling, absorbance of the resulting chomophore was determined at $532 \mathrm{~nm}$ using a UV visible spectrophotometer (Beckman DU 640B). MDA levels were determined using an extinction coefficient for MDA-TBA complex of $1.56 \times 10^{5} \mathrm{M} \times 1 \mathrm{~cm}^{-1}$.

\section{Plasma scavenging activities}

The free radical scavenging activities of plasma was measured using the DPPH radical method according to Brand-Williams et al., [27]. Briefly, $100 \mu \mathrm{L}$ of plasma sample were added to $2 \mathrm{ml}$ of 2,2-diphenyl-1-picrylhydrazyl (DPPH) in methanol solution $(100 \mathrm{mM})$. After incubation at $37{ }^{\circ} \mathrm{C}$ for $30 \mathrm{~min}, 1 \mathrm{~mL}$ of chloroform was added and the solution was centrifuged at $3000 \mathrm{~g}$ for $10 \mathrm{~min}$. The absorbance of clear supernatant was then determined at $517 \mathrm{~nm}$ using spectrophotometer (Beckman DU 640B). DPPH solution was used as a control and the plasma scavenging activities (PSA), expressed in percentage, was calculated according to the following equation:
PSA $(\%)=100 \times\left(\mathbf{A}_{517}(\right.$ control $) \times \mathbf{A}_{517}($ sample $) / \mathbf{A}_{517}($ control $)$.

\section{Antioxidant enzyme activities}

The activity of SOD was determined using modified epinephrine assays [28]. At alkaline $\mathrm{pH}$, superoxide anion $\mathrm{O}^{2 \cdot-}$ causes the autoxidation of epinephrine to adrenochrome; while competing with this reaction, SOD decreased the adrenochrome formation. One unit of SOD is defined as the amount of the extract that inhibits the rate of adenochrome formation by $50 \%$. Enzyme extract was added to $2 \mathrm{~mL}$ reaction mixture containing $10 \mu \mathrm{L}$ of bovine catalase $(0.4 \mathrm{U} / \mu \mathrm{L}), 20 \mu \mathrm{L}$ of epinephrine $(5 \mathrm{mg} /$ $\mathrm{mL}$ ) and $62.5 \mathrm{mM}$ of sodium carbonate/bicarbonate buffer $\mathrm{pH}$ 10.2. Absorbance was recorded at $480 \mathrm{~nm}$.

CAT activity was assayed by measuring the initial rate of $\mathrm{H}_{2} \mathrm{O}_{2}$ disappearance at $240 \mathrm{~nm}$ [29]. The reaction mixture contained $33 \mathrm{mM} \mathrm{H} \mathrm{H}_{2} \mathrm{O}_{2}$ in $50 \mathrm{mM}$ phosphate buffer $\mathrm{pH} 7.0$ and CAT activity was calculated using the extinction coefficient of $40 \mathrm{mM}^{-1} \mathrm{~cm}^{-1}$ for $\mathrm{H}_{2} \mathrm{O}_{2}$.

The activity of GPx was quantified following the procedure of Flohé and Günzler, [30]. Briefly, $1 \mathrm{~mL}$ of reaction mixture containing $0.2 \mathrm{~mL}$ of gastric supernatant, $0.2 \mathrm{~mL}$ of phosphate buffer $0.1 \mathrm{M} \mathrm{pH} 7.4,0.2 \mathrm{~mL}$ of GSH $(4 \mathrm{mM})$ and $0.4 \mathrm{~mL}$ of $\mathrm{H}_{2} \mathrm{O}_{2}(5 \mathrm{mM})$. The mixture was incubated at $37{ }^{\circ} \mathrm{C}$ for $1 \mathrm{~min}$ and the reaction was stopped by the addition of $0.5 \mathrm{~mL}$ TCA $(5 \%, w / v)$. After centrifugation at $1500 \mathrm{~g}$ for $5 \mathrm{~min}$, aliquot $(0.2 \mathrm{~mL})$ from supernatant was combined with $0.5 \mathrm{~mL}$ of phosphate buffer $0.1 \mathrm{M} \mathrm{pH} 7.4$ and $0.5 \mathrm{~mL}$ DTNB $(10 \mathrm{mM})$ and absorbance was read at $412 \mathrm{~nm}$. The activity of GPx was expressed as nmol of GSH consumed/min/mg protein.

\section{Non-enzymatic antioxidants measurement}

Thiol groups $(-\mathrm{SH})$ determination The total concentration of thiol groups $(-\mathrm{SH})$ was performed according to Ellman's method [31]. Briefly, homogenates of gastric mucosa were mixed with $800 \mu \mathrm{L}$ of $0.25 \mathrm{M}$ phosphate buffer (pH 8.2) and $100 \mu \mathrm{L}$ of $20 \mathrm{mM}$ EDTA, and the optical density was measured at $412 \mathrm{~nm}$ (A1). Then, $100 \mu \mathrm{L}$ of $10 \mathrm{mM}$ DTNB were added and incubated during $15 \mathrm{~min}$ and the absorbance of the sample was quantified at $412 \mathrm{~nm}$ (A2). The thiol groups concentration were calculated from $\mathrm{A} 1$ to $\mathrm{A} 0$ subtraction using a molar extinction coefficient of $13.6 \times 10^{3} \mathrm{M}^{-1} \times \mathrm{cm}^{-1}$. The results were expressed as $\mu \mathrm{mol}$ of thiol groups per $\mathrm{mg}$ of protein. GSH was estimated in gastric tissue by the method of Sedlak and Lindsay, [32]. Briefly $500 \mu \mathrm{L}$ of tissue homogenate prepared in $20 \mathrm{mM}$ EDTA, ( $\mathrm{pH} 4.7)$ were mixed with $400 \mu \mathrm{L}$ of cold distilled water and $100 \mu \mathrm{L}$ of $50 \%$ TCA. The samples were shaken using vortex mixer and centrifuged at $1200 \times \mathrm{g}$ during $15 \mathrm{~min}$. Following centrifugation, $2 \mathrm{~mL}$ of supernatant were mixed with $400 \mu \mathrm{L}$ 
of $400 \mathrm{mM}$ Tris-buffer (pH 8.9) and $10 \mu \mathrm{L}$ of $10 \mathrm{mM}$ DTNB. The absorbance was read at $412 \mathrm{~nm}$ against blank tube without homogenate.

$\mathrm{H}_{2} \mathrm{O}_{2}$ determination The gastric $\mathrm{H}_{2} \mathrm{O}_{2}$ levels were performed according to Dingeon et al., [33]. Briefly, the hydrogen peroxide reacts with p-hydroxybenzoic acid and 4-aminoantipyrine in the presence of peroxidase leading to the formation of quinoneimine that has a pink color detected at $505 \mathrm{~nm}$.

Iron measurement The gastric non-haem irons were measured colorimetrically using ferrozine as described by Leardi et al., [34]. Briefly, the iron dissociated from transferrin-iron complex by a solution of guanidine acetate was reduced by ascorbic acid and reacted with ferrozine leading to the formation of pink complex measured at $562 \mathrm{~nm}$.

Calcium determination The gastric calcium levels were performed using a colorimetric method according to Stern and Lewis, [35]. However at alkaline medium, calcium reacted with cresolphtalein leading to a colored complex measurable at $570 \mathrm{~nm}$.

\section{Protein determination}

Protein concentrations were determined according to Hartree [36], as is a slight change of the Lowry method [37]. Serum albumin was used as standard.

\section{Statistical analysis}

The data were analyzed by unpaired Student's $t$-test and were expressed as means \pm standard error of the mean (S.E.M.). The data are representative of 10 independent experiments. All statistical tests were two-tailed, and a $p$ value of 0.05 or less was considered significant.

\section{Results}

\section{Total polyphenols and flavonoids contents}

The aqueous extract of Citrus sinensis peel (CSPE) was firstly investigated for their phenolic compouds contents. As shown in Table 1, the CSPE exhibited high levels of total phenolics $(169.94 \pm 2.13 \mathrm{mg}$ gallic acid equivalence (GAE)/g dry matter (DM)] as well as total flavonoids $(87.48 \pm 1.59 \mathrm{mg}$ quercetin equivalents $(\mathrm{QtE}) / \mathrm{g} \mathrm{DM})$.

\section{In vitro antioxidant capacity}

Concerning the antioxidant capacity, we have found that the radical-scavenging activity of CSPE against superoxide anion and DPPH radicals increased significantly in a dose-dependent manner. The $\mathrm{IC}_{50}$ values corresponding to the amount of the fraction required to scavenge $50 \%$ of $\mathrm{DPPH}$ and $\mathrm{O}_{2}^{--}$radicals are respectively 188.49 and $198.4 \mu \mathrm{g} / \mathrm{mL}$. However, regarding quercetin, used as reference molecule, the $\mathrm{IC}_{50}$ values are 61.84 and $126.83 \mu \mathrm{g} / \mathrm{mL}$, respectively for $\mathrm{DPPH}$ and $\mathrm{O}_{2}^{--}$radicals (Table 1).

\section{Quantitative macroscopic evaluation of CSPE anti-ulcer activities}

Concerning the macroscopic examinations, animals intoxicated with ethanol showed an extensive elongated thick, dark red and black band of hemorrhagic lesions on the glandular part of the stomach. Quantitative examination showed that CSPE, Hesperidin or reference drug pre-treatment significantly and dose-dependently reduced the ulcer index, and ameliorated the protection percentage of injury induced by EtOH administration (Table 2).

\section{Histopathological evaluation of gastric lesions}

Histological observation of ethanol-induced gastric lesions in $\mathrm{EtOH}$ group showed a comparative extensive congestion, surface coating alteration, necrotic lesions, edema, epithelial and vascular cells alteration, haemorrhage and hyperaemia as well as inflammatory cell infiltration in the stomach (Fig. 1) mucosa and submucosa. Pretreatment with CSPE and Hesperidin or reference drug presents a clear dose-dependent protection of the gastric mucosa as seen by reduction of lesions, mucosal and submucosal edema as well as leucocytes infiltration. A similar protective effect had also observed in Hesperidin and omeprazole pre-treated rats.

\section{Gastric tumor necrosis factor alpha (TNF-a)}

Gastric TNF- $\alpha$, a major pro-inflammatory cytokine, show any significant change in both and hesperidin and CSPE pretreated rats compared to untreated ulcer rats as shown in Fig. 2. A similar protective effect had also observed with Omeprazole-induced a significant reduction in gastric TNF- $\alpha$ compared to treat ulcerated rats $(P<0.05)$.

Table 1 Total polyphenols and flavonoids contents and IC50 values of the DPPH and superoxide anion free radicals scavenging assay of the CSPE and quercetin

\begin{tabular}{lllll}
\hline & Total phenolic content $(\mathrm{mg} \mathrm{GAE} / \mathrm{g})$ & Total flavonoids content $(\mathrm{mg}$ QE/g) & $\begin{array}{l}\text { DPPH } \\
\mathrm{IC}_{50}(\mu \mathrm{g} / \mathrm{ml})\end{array}$ & $\begin{array}{l}\text { Superoxide anion } \\
\mathrm{IC}_{50}(\mu \mathrm{g} / \mathrm{ml})\end{array}$ \\
\hline CSPE & $169.94 \pm 2.13$ & $87.48 \pm 1.59$ & 188.49 & 198.4 \\
Quercetin & $\mathrm{nt}$ & $\mathrm{nt}$ & 61.4 & 126.83 \\
\hline
\end{tabular}


Table 2 Effect of Citrus sinensis peel extract (CSPE), Omeprazole $(\mathrm{OM})$ and Hesperidin $(\mathrm{H})$ on gastric macroscopic alterations induced by EtOH: ulcer index and Percentage of protection (\%). Animals were pretreated with various doses of CSPE (100, 200 and $400 \mathrm{mg} / \mathrm{kg}$, p.o.), OM (20 mg/kg, b.w., p.o.), H (50 mg/kg, p.o)

\begin{tabular}{lll}
\hline Pre-traitement & \multicolumn{2}{l}{ Stomach } \\
\cline { 2 - 3 } & $\begin{array}{l}\text { Ulcer area }\left(\mathrm{mm}^{2}\right) \\
(\text { Mean } \pm \text { S.E.M) }\end{array}$ & Percentage of protection (\%) \\
\hline Control & 0 & - \\
$\mathrm{EtOH}$ & $98.50 \pm 3.59^{*}$ & - \\
$\mathrm{EtOH}+\mathrm{CSPE}-100$ & $71.60 \pm 1.9^{* *}$ & $27.26 \%$ \\
$\mathrm{EtOH}+$ CSPE-200 & $47.60 \pm 1.88^{* *}$ & $53.19 \%$ \\
$\mathrm{EtOH}+$ CSPE-400 & $11.20 \pm 0.86^{* *}$ & $89.80 \%$ \\
$\mathrm{EtOH}+$ Omeprazole & $21.34 \pm 1.72^{* *}$ & $78.16 \%$ \\
$\mathrm{EtOH}+$ Hesperidin & $26.42 \pm 1.74^{* *}$ & $73.60 \%$
\end{tabular}

The data are expressed as mean \pm S.E.M. $(n=10) * p<0.05$ compared to control group and ${ }^{* *} p<0.05$ compared to $\mathrm{EtOH}$ group

\section{Cyclooxygenase COX-2 gene expression}

The real-time PCR assays showed that COX-2 mRNA was increased $2 \mathrm{~h}$ after $\mathrm{EtOH}$ administration in the rats stomach mucosa $(P<0.05)$. In addition, CSPE decreased COX-2 mRNA expression when compared to ulcerated untreated rats (Fig. 3), this decrease presents a clear dose-dependent. In addition, Omeprazole and hesperidin had significant effects on COX-2 mRNA expression when compared to ulcerated rats.

\section{Effects on plasma scavenging activity}

$\mathrm{EtOH}$ administration significantly decreased the plasma scavenging activity as compared to control group (Fig. 4). By contrast, PSA percentage was significantly and dosedependently increased after CSPE pre-treatment. Similar effects were also observed for omeprazole and hesperidin, used as reference molecules.

\section{Effect of CSPE and hesperidin on EtOH-induced gastric lipoperoxidation and hydrogen peroxide increase}

Bearing on the effect of EtOH, CSPE and hesperidin on oxidative stress condition, we firstly studied the gastric lipoperoxidation and hydrogen peroxide content (Fig. 5). $\mathrm{EtOH}$ intoxication drastically increased the gastric MDA and $\mathrm{H}_{2} \mathrm{O}_{2}$ levels (Fig. 5a and b). CSPE pre-treatment significantly and dose dependently reversed lipoperoxidation and hydrogen peroxide increase induced by EtOH intoxication. The same results were observed with omeprazole and hesperidin pre-treated rats.

\section{Effect of CSPE and hesperidin on EtOH-induced gastric -SH groups decrease}

We also showed that thiol group's level was significantly reduced in the gastric mucosa of ethanol-treated rats. However, CSPE (100, 200 and $400 \mathrm{mg} / \mathrm{kg}$, b.w. p.o.), hesperidin $(50 \mathrm{mg} / \mathrm{kg}$, b.w. p.o.) or omeprazole $(20 \mathrm{mg} / \mathrm{kg}$, b.w. p.o.) pre-treatment significantly protected against this decrease as compared to EtOH group (Fig. 5c).

\section{Effect of CSPE and hesperidin on EtOH-induced antioxidant enzyme activities depletion}

We further looked at the effect of EtOH, CSPE and hesperidin on antioxidant enzymes activities in gastric mucosa (Fig. 6). Alcohol, significantly decreased antioxidant enzyme activities such as SOD (A), CAT (B) and GPx (C). However, subacute pre-treatment with Citrus sinensis peel aqueous extract, hesperidin and omeprazole significantly reduced the EtOH-induced decrease in antioxidant status to near control levels especially with the highest dose of CSPE $400 \mathrm{mg} / \mathrm{kg}$ b.w.

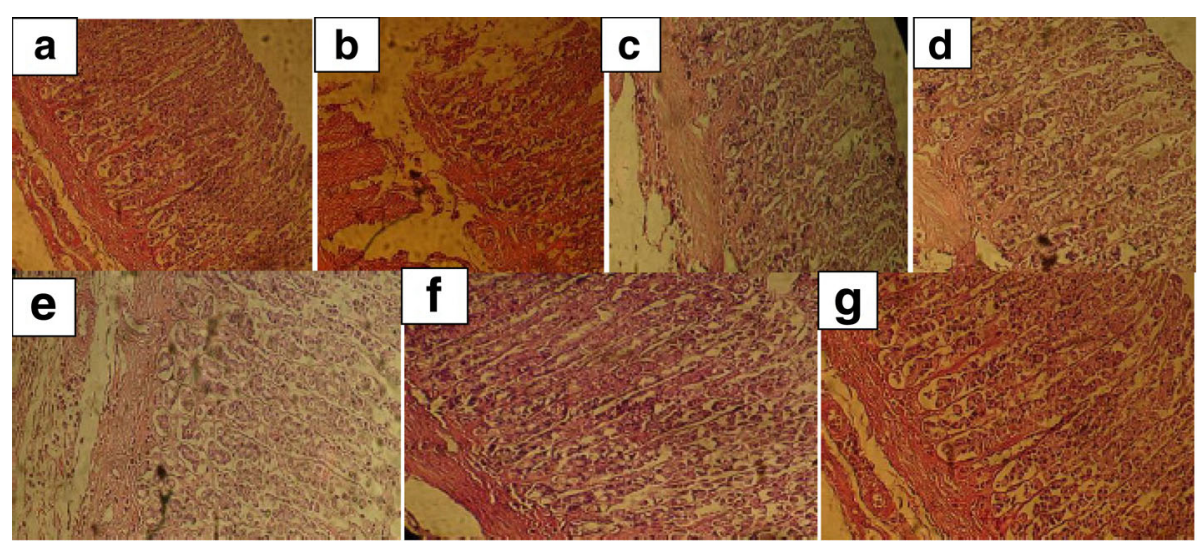

Fig. 1 Gastric histology showing the protective effects of Citrus sinensis peel extract (CSPE), Hesperidin (H) and Omeprazole (OM) on EtOH-induced histological alteration in stomach. Animals were pre-treated with various doses of CSPE (100, 200 and 400 mg/kg, b.w., p.o.), OM (20 mg/kg, b.w., p.o.), Hesperidin (50 mg/kg, b.w., p.o) or bi-distilled water, challenged with a single oral administration of EtOH (4 g/kg, b.w., p.o.) or NaCl $9 \%$ o for two hours. a: control; b: EtOH; c: EtOH+ CSPE-100; d: EtOH+ CSPE-200; e: EtOH+ CSPE-400 and f: EtOH+ H; $\mathbf{g}: \mathrm{EtOH}+\mathrm{OM}$ ). The data are expressed as mean \pm S.E.M. $(n=10) *: p<0.05$ compared to the control group and \#: $p<0.05$ compared to the $\mathrm{EtOH}$ group 


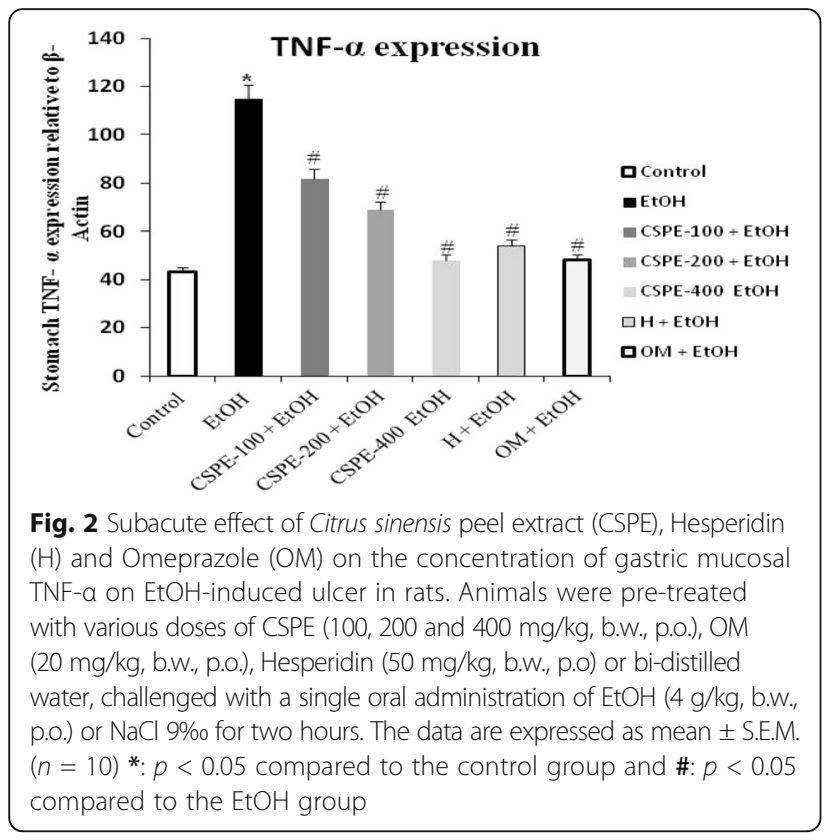

\section{Effects on free iron and calcium}

Bearing on the effect of EtOH, CSPE and hesperidin on intracellular mediators such as free iron and calcium levels in gastric mucosa (Table 3). Ethanol group showed a significant decrease in free iron and ionizable calcium levels in gastric tissues when compared to control group. However, the Citrus sinensis peel aqueous extract (CSPE) treatment significantly and dose-dependently reduced the $\mathrm{EtOH}$-induced intracellular mediators deregulation. A similar protective effect had also observed in Hesperidin $(\mathrm{H})$ and omeprazole $(\mathrm{OM})$ in pre-treated rats.

\section{Discussion}

Medicinal plants are sources of some well known antiulcer drugs such as: liquorice (dehydroglycerrizinic acid), Piper betel L. (piperine), Emblica officinalis (embline), Terminalia bellerica and Terminalia chebula mostly in the category of glycosides and flavonoids [38]. Hesperidin is a flavanone glycoside abundant in orange peel especially Citrus sinensis and is an economical by-product of citrus. The present study was designed to investigate the antiulcer activity of Citrus sinensis peel aqueous extract and hesperidin isolated from $C$. sinensis on oxidative damageinduced gastric ulcer models, looking into its potential antioxidant and anti-inflammatory properties.

In vitro, our phytochemical study firstly showed that CSPE presents a powerful scavenging action against $\mathrm{DPPH}$ radical and superoxide anion with lower $\mathrm{IC}_{50}$ values (188.49 and $198.4 \mu \mathrm{g} / \mathrm{mL}$, respectively). However, similar free radical-scavenging activities were previously

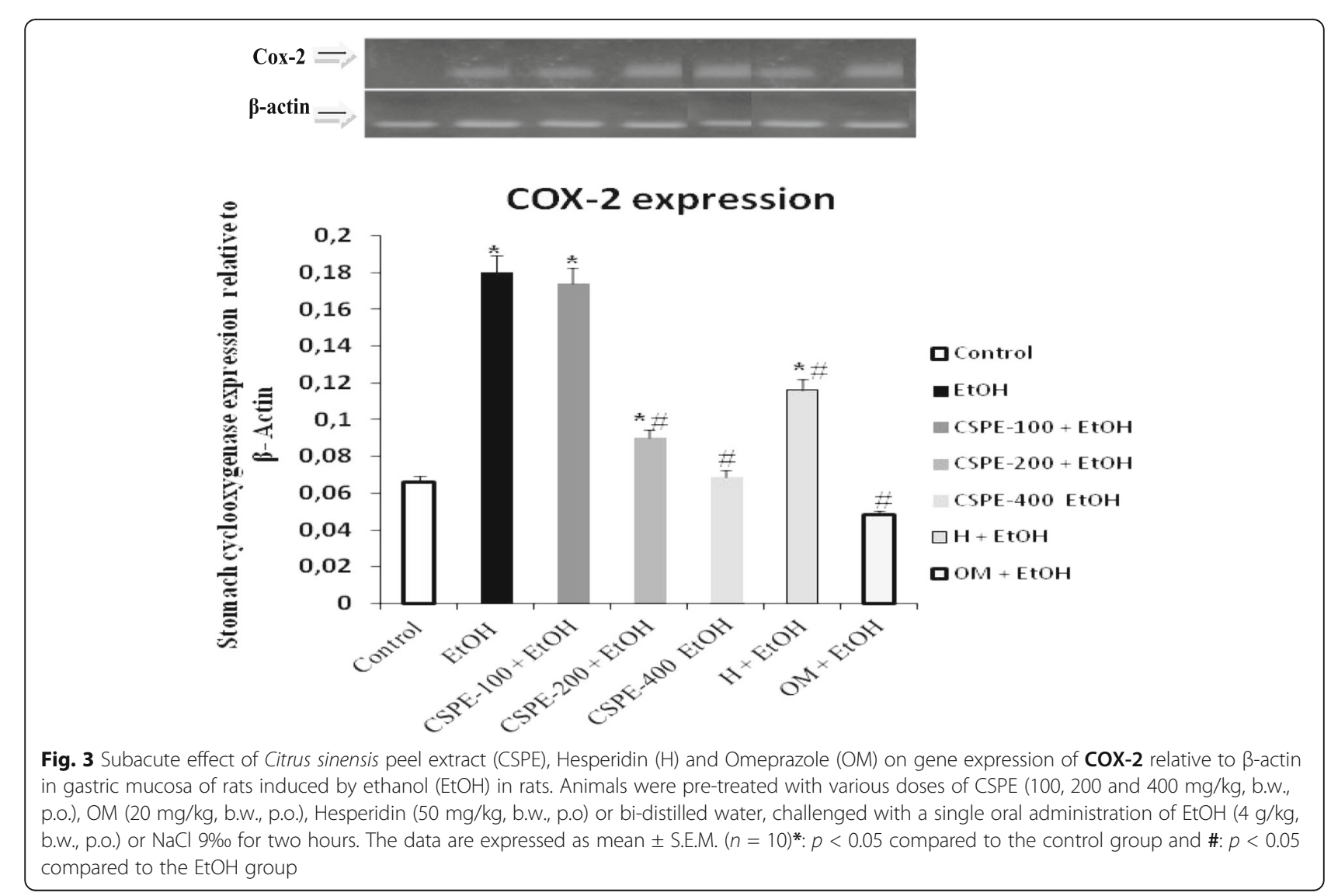




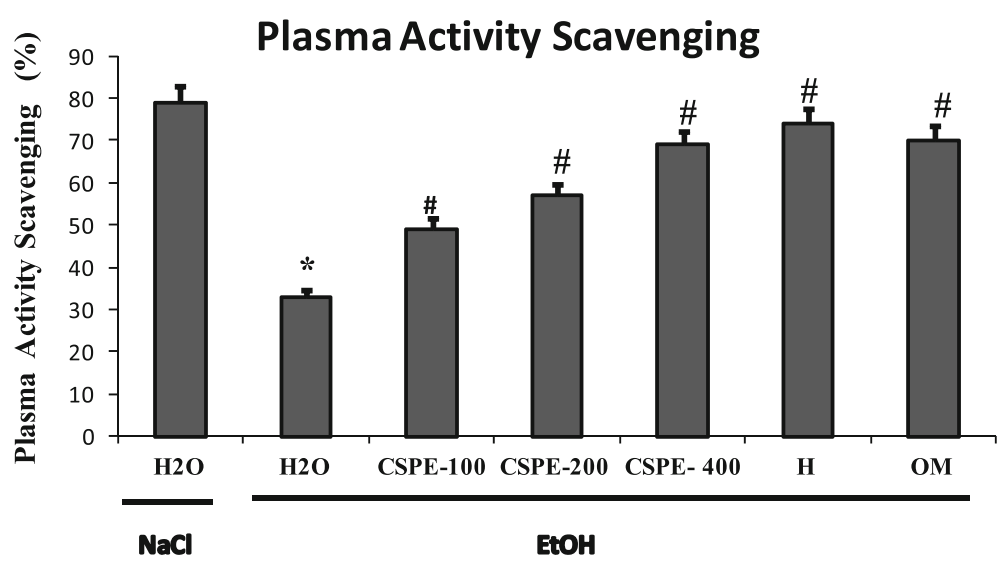

Fig. 4 Subacute effect of Citrus sinensis peel extract (CSPE), Hesperidin (H) and Omeprazole (OM) on EtOH-induced disturbances in plasma scavenging activity (PSA). Animals were pre-treated with various doses of $\operatorname{CSPE}(100,200$ and 400 mg/kg, b.w., p.o.), OM (20 mg/kg, b.w., p.o.), Hesperidin (50 mg/kg, b.w., p.o) or bi-distilled water, challenged with a single oral administration of EtOH ( $4 \mathrm{~g} / \mathrm{kg}$, b.w., p.o.) or NaCl $9 \%$ for two hours. The data are expressed as mean \pm S.E.M. $(n=10)^{*}: p<0.05$ compared to the control group and \#: $p<0.05$ compared to the EtOH group

observed for other plant extracts but lesser than CSPE $[39,40]$. The antioxidant activity of CSPE could be, in part, attributed to its high phenolic compounds levels. In this context, our data also suggest that CSPE presents a high concentration of total polyphenols $(169.94 \pm 2.13 \mathrm{mg}$ GAE/g), flavonoids $(87.48 \pm 1.59 \mathrm{mg} \mathrm{QE} / \mathrm{g})$. This antioxidant capacity of Citrus sinensis peel aqueous extract is mainly related to the higher level of phenolic compouds in this fraction [41]. However, these molecules are the major source of their capacity of scavenging free radicals such as superoxide anion $\left(\mathrm{O}_{2}\right)$ and hydroxyl radical $\left(\mathrm{OH}^{-}\right)$[42].

In vivo, we firstly showed that alcohol administration clearly altered the gastric mucosa and submucosa. These lesions are accompanied by edema, epithelial and vascular cells alteration, necrosis and leucocytes infiltration of the submucosal layer. Our data are in line with previous report using EtOH as ulceration inducer [43, 44]. Several mechanisms are implicated in the development of alcohol-induced lesions in the mucous membranes [45]. Ethanol is considered one of the agents that induce gastric ulcers. The effects of ethanol on gastric mucosa are complicated and multifaceted that may be associated with a disturbance in the balance between gastric mucosal protective and aggressive factors [46]. Ethanol causes injures in the vascular endothelial cells of the gastric mucosa and induces microcirculatory disturbance and hypoxia, linking to the overproduction of oxygen radicals [47]. ROS are produced within the gastrointestinal tract, but their roles in pathophysiology and disease pathogenesis have not been well studied.

Subacute treatment with CSPE protects against gastric lesions induced by $\mathrm{EtOH}$ administration and allowed to the reduction of morphological and histopathological observed signs. This therapeutic effect, using CSPE high dosage ( $400 \mathrm{mg} / \mathrm{kg}$ b.w; o.p), is more effective than reference molecules such as omeprazole (78.16 and 80.20\%) and hesperidin (73.60 and $81.45 \%$ ), respectively for the stomach mucosa.

Gastric TNF- $\alpha$, a major pro-inflammatory cytokine, show a significant change in both CSPE and hesperidin treated rats compared to untreated ulcer rats as shown in Fig. 2. Omeprazole induced a significant reduction in gastric TNF- $\alpha$ compared to untreat ulcerated rats $(P<0.05)$.

The real-time PCR assays showed that COX-2 mRNA was increased $2 \mathrm{~h}$ after $\mathrm{EtOH}$ administration in the mucosa of the rats $(P<0.05)$. In addition, CSPE especially the higher dose and hesperidin decreased COX-2 mRNA expression when compared to ulcerated untreated rats (Fig. 5). The same effect was observed after omeprazole administration when compared to untreated ulcerated rats.

We also showed in the present study that EtOH intoxication induced an increase of lhe final products of lipid peroxidation, decrease of thiol group levels, increase of hydrogen peroxide content as well as depletion antioxidant enzyme activities such as GPx, CAT and SOD. Acute alcohol-induced oxidative stress was commonly documented in gastric mucosa [48], liver [49], kidney [50], heart [51] and brain [52]. Ethanol administration provoked oxidative imbalance through a number of pathways including the generation of reactive oxygen species [53]. Lipid peroxidation level is an indicator of the generation of ROS in the tissue. However, SOD converts the reactive superoxide radical to $\mathrm{H}_{2} \mathrm{O}_{2}$, which was decreased in the gastric mucosa and if not scavenged by CAT, it can by itself cause lipid 

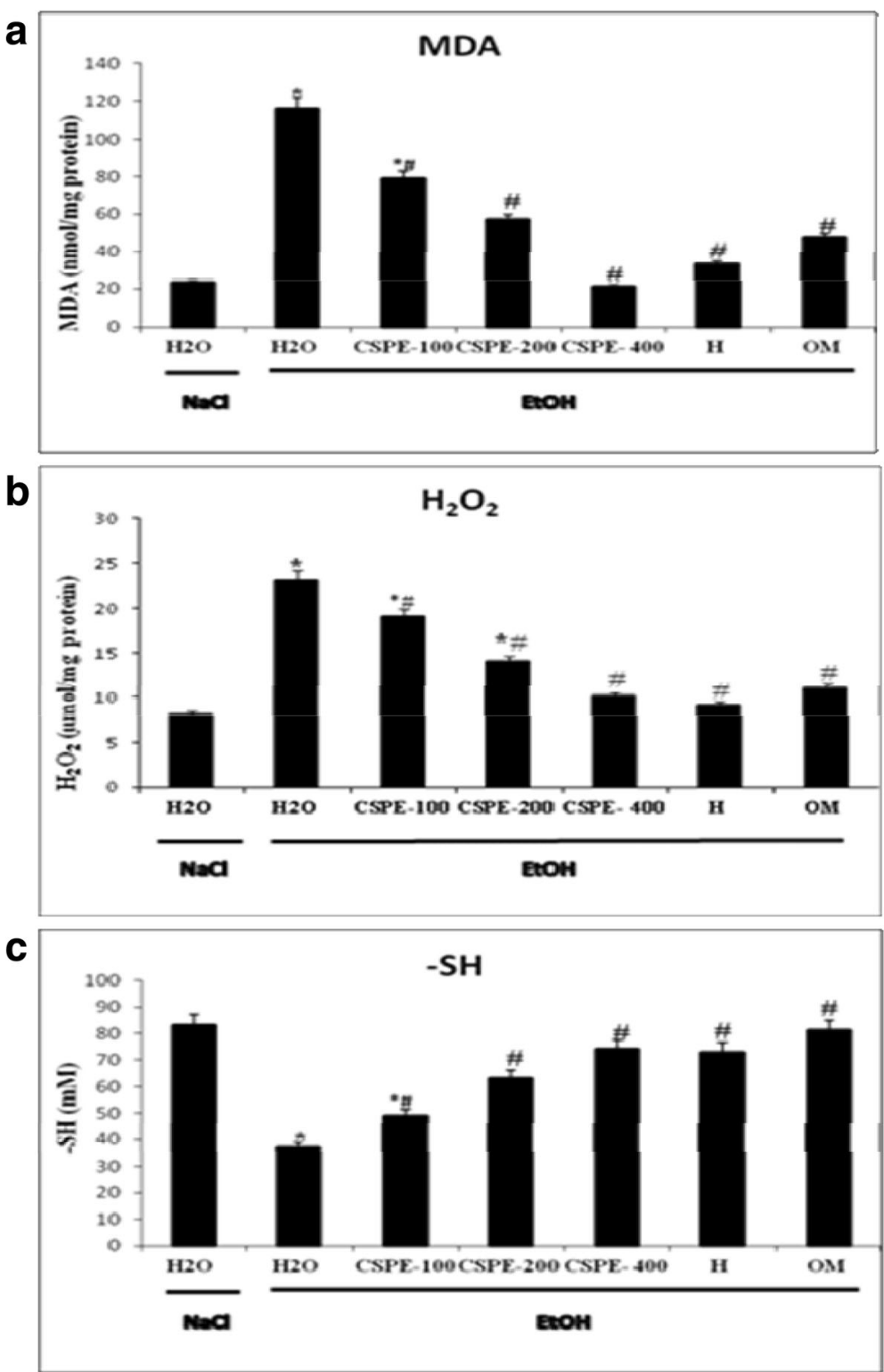

Fig. 5 Subacute effect of Citrus sinensis peel extract (CSPE), Hesperidin (H) and Omeprazole (OM) and ethanol (EtOH)-induced changes in stomach mucosa on MDA (a), $\mathrm{H}_{2} \mathrm{O}_{2}(\mathbf{b})$ and $-\mathrm{SH}$ (c) levels in rats induced by ethanol $(\mathrm{EtOH})$ in rats. Animals were pre-treated with various doses of CSPE (100, 200 and 400 mg/kg, b.w., p.o.), OM (20 mg/kg, b.w., p.o.), Hesperidin (50 mg/kg, b.w., p.o) or bi-distilled water, challenged with a single oral administration of $\mathrm{EtOH}(4 \mathrm{~g} / \mathrm{kg}$, b.w., p.o.) or $\mathrm{NaCl} 9 \%$ for two hours. The data are expressed as mean \pm S.E.M. $(n=10) *$ : $p<0.05$ compared to the control group and \#: $p<0.05$ compared to the EtOH group

peroxidation by generation of hydroxyl radical [54]. More importantly, we showed that Citrus sinensis peel and hesperidin pre-treatment abolished acute EtOHinduced oxidative stress in the gastric mucosa. These data fully corroborated all previously reported in vivo [55] and in vitro [56] antioxidant and anti-inflammatory properties of CSPE. These finding corroborate with previous study wich have reported that the aqueous extract of CSPE contains a good amount of total polyphenols, total flavonoïds and condensed tannins [57]. These molecules are the primal source of the antioxidant ability of this plant, by scavenging free radicals as hydroxyl radical $\left(\mathrm{OH}^{*}\right)$ which is the major cause of lipid peroxidation [58]. In addition, it is well known that sulfhydryls are in part involved in gastric cytoprotection [59] and also in the maintain of mucosal barrier integrity and scavenge free radicals formed due to the action of noxious agents [60]. 


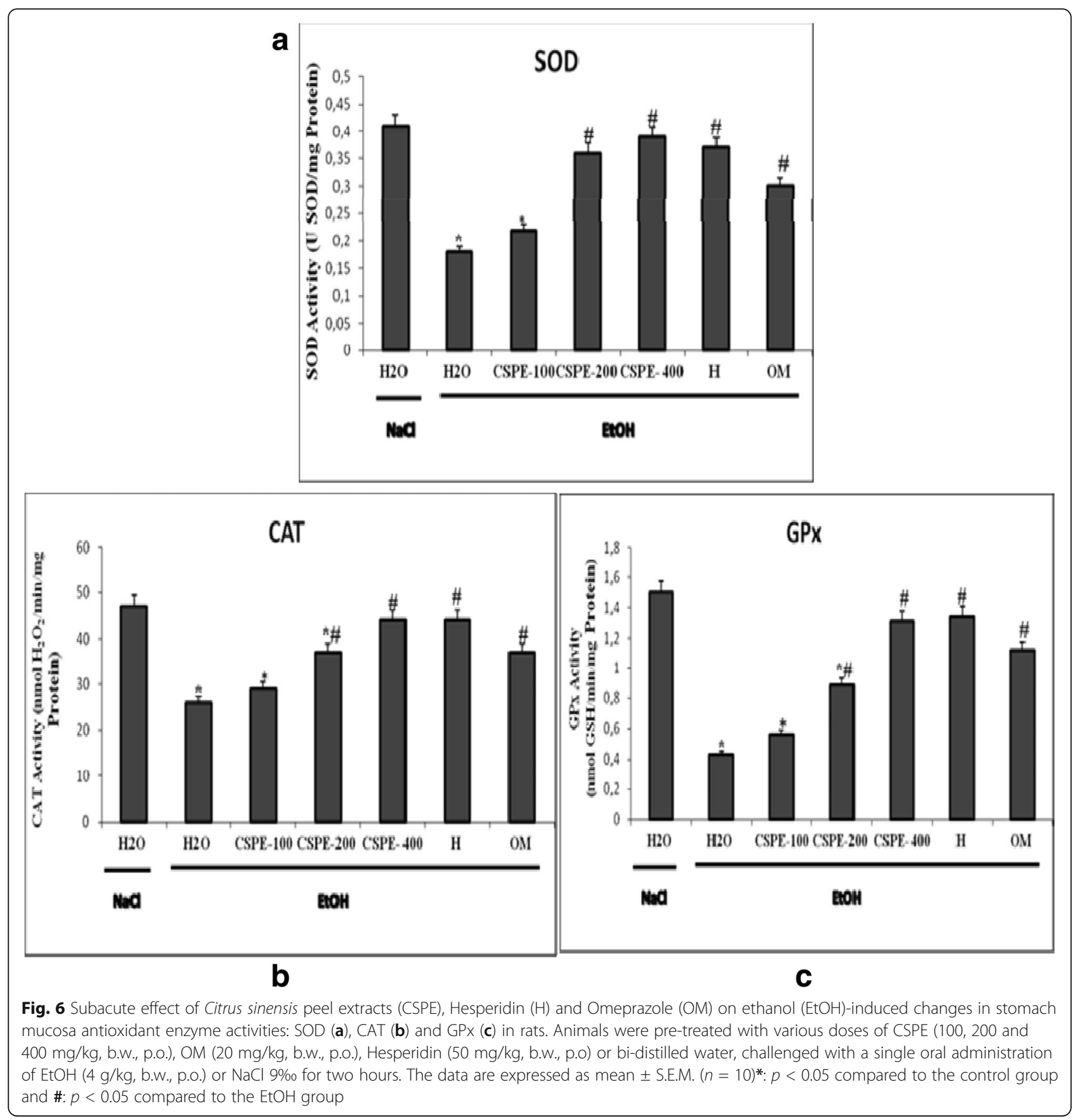

More importantly, this study showed an increase in gastric and duodenal ionizable calcium in response to oxidative stress induced by ethanol administration. This result corroborated several previous studies [61, 62]. However, we can now speculate that CSPE, exerts its beneficial effect by chelating free iron and scavenging $\mathrm{H}_{2} \mathrm{O}_{2}$ leading to calcium homeostasis. Our results also suggest that pretreatment with CSPE protects against overloading of cells of the gastric and duodenal mucosa by free iron and $\mathrm{H}_{2} \mathrm{O}_{2}$ induced by ethanol sub-acute exposure. Nevertheless, free iron and hydrogen peroxide are the two components of the Fenton's reaction, which is involved in the generation of hydroxyl radical $\left(\mathrm{OH}^{*}\right)$ [63]. However, this later is the most powerful oxidant that can attack the molecular structures and thus play a major role in oxidative damage [64]. Living organisms so, develop a complex endogenous and exogenous antioxidant defense system to block the production of this harmful radical [65]. 
Table 3 Effect of Citrus sinensis peel extract (CSPE), Hespiridin (H) and Omeprazole (OM) on EtOH-induced disturbance in gastric $\mathrm{H}_{2} \mathrm{O}_{2}$, free iron and calcium levels. Animals were pretreated with various doses of CSPE (100, 200 and 400 mg/kg, p.o.), OM (20 mg/ kg, b.w., p.o.), $\mathrm{H}(50 \mathrm{mg} / \mathrm{kg}$, p.o) or $\mathrm{NaCl} 9 \%$

\begin{tabular}{lll}
\hline Pretreatment & $\begin{array}{l}\text { Free iron } \\
(\mu \mathrm{mol} / \mathrm{mg} \text { protein })\end{array}$ & $\begin{array}{l}\text { Calcium } \\
(\mathrm{mmol} / \mathrm{mg} \text { protein })\end{array}$ \\
\hline Control & $18.08 \pm 1.06$ & $101.69 \pm 6.91$ \\
$\mathrm{EtOH}$ & $42.14 \pm 2.43^{*}$ & $194.18 \pm 16.13^{*}$ \\
$\mathrm{EtOH}+\mathrm{CSPE}-100$ & $33.36 \pm 1.38^{* *}$ & $142.64 \pm 9.46^{* *}$ \\
$\mathrm{EtOH}+\mathrm{CSPE}-200$ & $26.12 \pm 1.17^{* *}$ & $129.88 \pm 7.68^{* *}$ \\
$\mathrm{EtOH}+\mathrm{CSPE}-400$ & $19.68 \pm 1.53^{* *}$ & $113.99 \pm 9.19^{* *}$ \\
$\mathrm{EtOH}+$ Omeprazole & $22.29 \pm 1.67^{* *}$ & $117.44 \pm 14.27^{* *}$ \\
$\mathrm{EtOH}+$ Hesperidin & $20.76 \pm 1.20^{* *}$ & $104.38 \pm 13.26^{* *}$ \\
\hline
\end{tabular}

The data are expressed as mean \pm S.E.M. $(n=10) * p<0.05$ compared to control group and ${ }^{* *} p<0.05$ compared to EtOH group

\section{Conclusion}

In conclusion, Citrus sinensis peel aqueous extract and its major flavonoid, hesperidin, pre-treatment protects against gastric ulcer induced by ethanol in rats. Both compounds decreased COX-2 expression and gastric DNA fragmentation. Both drugs have successfully reduced TNF- $\alpha$ production and corrected the increased gastric lipid peroxidation. Therefore, these extract and flavanone exert anti-inflammatory and antioxidant properties and it is preferable to administer them under various inflammatory conditions to avoid the aggravation of the ulcers.

\section{Abbreviations}

CAT: Catalase; CSPE: Citrus sinensis peel extract: DPPH: 2,2-diphenyl-1picrylhydrazyl; GPx: Glutathione peroxidase; $\mathrm{H}$ : Hesperidin; $\mathrm{H}_{2} \mathrm{O}_{2}$ : Hydrogen peroxide; MDA: Malondialdehyde; OM: Omeprazole; SOD: Superoxide dismutase

\section{Acknowledgements}

Financial support of the Tunisian Ministry of Higher Education and Scientific Research is gratefully acknowledged.

\section{Funding}

This review was written independently; no company or institution supported it financially.

\section{Availability of data and materials}

Data sharing not applicable to this article as no datasets were generated or analysed during the current study.

\section{Authors' contributions}

SS contributed to the study concept and design, data acquisition and interpretation, and drafting of the manuscript; KR, DG, and SH contributed to critical revision of the manuscript; and SS and LM contributed to the study concept and design, drafting of the manuscript, critical revision and final approval, and submission of the manuscript. SS, KR, DG and HS designed and performed the study, wrote the manuscript. SS, HS, RT, DG, and LM performed the study. All authors approved the final version of the text.

\section{Ethics approval and consent to participate}

Experimental protocols were approved with the guidelines of the Ethical Committee of Science Faculty of Tunis, Tunisia. The test was performed in compliance with the Commission Directive 2000/32/EC and the OECD Guideline 474
Consent for publication

Not applicable.

\section{Competing interests}

The authors declare that they have no competing interests.

\section{Publisher's Note}

Springer Nature remains neutral with regard to jurisdictional claims in published maps and institutional affiliations.

Received: 3 July 2017 Accepted: 2 August 2017

Published online: 14 August 2017

References

1. Feinstein LB, Holman RC, Christensen KL, Steiner CA, Swerdlow DL. Swerdlow Trends in Hospitalizations for Peptic Ulcer Disease, United States, 1998-2005. Emerg Infect Dis. 2010;16(9):1410-8.

2. Thorsen K, Søreide JA, Kvaløy JT, Glomsaker T, Søreide K. Epidemiology of perforated peptic ulcer: age- and gender-adjusted analysis of incidence and mortality. World J Gastroenterol. 2013;19:347-54

3. Mota KSL, Dias GEN, Pinto MEF, Luiz-Ferreira A, Souza-Brito ARM, Hiruma-Lima CA, Barbosa-Filho JM, Batista LM. Flavonoids with gastroprotective activity. Molecules. 2009:14:979-1012.

4. Paguigan ND, Castillo DHB, Chichioco-Hernandez CL. Anti-ulcer activity of leguminosae plants. Arq Gastroenterol. 2014;51:815-29.

5. Hunt RH, Camilleri M, Crowe SE, El-Omar EM, Fox JG, Kuipers EJ, Malfertheiner P, McColl KEL, Pritchard DM, Rugge M, Sonnenberg A, Sugano K, Tack J. The stomach in health and disease. Recent Adv Clin Pract. 2015; 64(10):1650-68.

6. Oliveira CP, Kassab P, Lopasso FP, Souza HP, Janiszewski M, Laurindo FR. Protective effect of ascorbic acid in experimental gastric cancer: reduction of oxidative stress. World J Gastroenterol. 2003:9:446-8.

7. Kountouras J, Chatzopoulos D, Zavos C. Reactive oxygen metabolites and upper gastrointestinal diseases. Hepato-Gastroenterol. 2001;8:743-51.

8. Guslandi M. Effects of ethanol on the gastric mucosa. Digest Dis Sci. 1987:5:21-32.

9. Kangwan N, Park JM, Hahm KB. Development of Gl-safe NSAID: progression from the bark of willow tree to modern pharmacology. Curr Opin Pharmacol. 2014;19:17-23.

10. Jaime AR, Cristina T, Tania Y, Jose B, Guillermo S. Gastroprotective and ulcer healing effect of ferruginol in mice and rats: Assessment of its mechanism of actionusing in vitro models. Life Sci. 2006;78:2503-9.

11. Fathiazad F, Afshar J. An investigation of methylation methods of hesperidin. Daru. 2004;12:67-70.

12. Aghel N, Ramezani Z, Beiranvand S. Hesperidine from citrus sinensis cultivated in dezful. Iran Pak J Biol Sci. 2008;20:2451-3.

13. Rotelli AE, Guardia T, Juárez AO, De L, Pelzer LE. Comparative study of flavonoids in experimental models of inflammation. Pharmacol Res. 2003:48:601-6.

14. Navarri-Izzo F, Pinzino C, Quartacci MF, Sgherri CLM. Intracellular membranes: kinetics of superoxide production and changes in thylakoids of resurrection plants upon dehydration and rehydration. Proc $\mathrm{R}$ Soc Edinburgh Sec B. 1994;102 B:187-91.

15. Bernatova I, Pechanova O, Babal P, Kysela S, Stvrtina S, Andriantsitohaina R. Wine polyphenols improve cardiovascular remodeling and vascular function in NO-deficient hypertension. Am J Physiol Heart Circ Physiol. 2002;282:H942-8.

16. Knekt P, Kumpulainen J, Jarvinen R, Rissanen H, Heliovaara M, Reunanen A Hakulinen T, Aromaa A. Flavonoid intake and risk of chronic diseases. Am J Clin Nutr. 2002;76:560-8.

17. Anila L, Vijayalakshmi NR. Antioxidant action of flavonoids from Mangifear indica and Emblica officinalis in hypercholesterolemic rats. Food Chem. 2003:83:569-74.

18. Hitzenberger $\mathrm{G}$. Therapeutic effectiveness of flavonoids illustrated by daflon 500 mg. Wein Med Wochenschr. 1997;174:409-12.

19. Manthey JA, Grohmann K. Concentrations of hesperidin and other orange peel flavonoids in citrus processing byproducts. J Agric Food Chem. 1996;44:811-4.

20. Haseeb N, John S, Gauri M, Yukio K. Extraction of polyphenols from grape seeds and concentration by ultrafiltration. Sep Purif Technol. 2006;48:176-81. 
21. Chang CY, Kuan YH, Li JR, Chen WY, Ou YC, Pan HC. Docosahexaenoic acid reduces cellular inflammatory response following permanent focal cerebral ischemia in rats. J Nutr Biochem. 2013;24:2127-37.

22. Grzegorczyk I, Matkowski A, Wysokinska H. Antioxidant activity of extracts from in vitro cultures of Salvia officinalis L. Food Chem. 2007;104:536-41.

23. Marklund S, Marklund G. Involvement of the superoxide anion radical in the autoxidation of pyrogallol and a convenient assay for superoxide dismutase. Eur J Biochem. 1974:47:469-74.

24. Maskos K, Fernandez-Catalan C, Huber R, Bourenkov GP, Bartunik H, Ellestad GA, Reddy P, Wolfson MF, Rauch CT, Castner BJ, Davis R, Clarke HR, Petersen M, Fitzner JN, Cerretti DP, March CJ, Paxton RJ, Black RA, Bode W. Crystal structure of the catalytic domain of human tumor necrosis factor-alphaconverting enzyme. Proc Natl Acad Sci U S A. 1998;95:3408-12.

25. Walch L, Morris PL. Cyclooxygenase 2 pathway mediates IL-1 beta regulation of IL-1alpha-1 beta, and IL-6 mRNA levels in Leydig cell progenitors. Endocrinology. 2002;143:3276-83.

26. Draper $\mathrm{HH}$, Hadley M. Malondialdehyde determination as index of lipid peroxidation. Methods Enzymol. 1990;186:421-31.

27. Brand-Williams W, Cuvelier ME, Berset C. Use of a free radical method to evaluate antioxidant activity. LWT Food Sci Technol. 1995;28:25-30.

28. Misra HP, Fridovich I. The role of superoxide anion in autoxidation of epinephrine and a simple assay for superoxide dismutase. J Biol Chem. 1972;247:3170-5.

29. Aebi H. Catalase in vitro. Methods Enzymol. 1984;105:121-6.

30. Flohé L, Günzler WA. Assays of glutathione peroxidase. Methods Enzymol. 1984;105:114-21.

31. Ellman GL. Tissue sulfhydryl groups. Arch Biochem Biophys. 1959;82:70-7.

32. Sedlak J, Lindsay RH. Estimation of total, protein-bound, and non-protein sulfhydryl groups in tissue with Ellman's reagent. Anal Biochem. 1968;25:192-205.

33. Dingeon B, Ferry JP, Roullet A. Automatic assay of blood sugar by Trinder's method. Ann Biol Clin. 1975;33:3-13.

34. Leardi A, Caraglia M, Selleri C, Pepe S, Pizzi C, Notaro R. Desferioxamine increases iron depletion and apoptosis induced by ara-C of human myeloid leukaemic cells. Br J Haematol. 1998:102:746-52.

35. Stern J, Lewis $\mathbf{W H}$. The colorimetric estimation of calcium in serum with ocresolphthalein complexone. Clin Chim Acta. 1957;2:576-80.

36. Hartree EF. Determination of protein: a modification of the Lowry method that gives a linear photometric response. Anal Biochem. 1972:48:422-7.

37. Lowry OH, Rosebrough NJ, Farr AL, Randall RJ. Protein measurement with the Folin phenol reagent. J Biol Chem. 1951;193:265-75.

38. Maurya RC, Srivastava UC. Cytoarchitecture of the cerebral hemisphere of Indian Wall Lizard, Hemidactylus flaviviridis (Rüppell). Nat Acad Sci Lett. 2011;34(11 \& 12):431-6.

39. Kelebek H, Selli S, Canbas A, Cabaroglu T. HPLC determination of organic acids, sugars, phenolic compositions and antioxidant capacity of orange juice and orange wine made from a Turkish cv. Kozan Microchem J. 2009; 91:187-92.

40. Zhao JH, Wojtek PM, Catherine W, Li L, Xu H-S, Peter RL, Scott J, Yan MZ, Xiujuan JD. Controlling cell growth on titanium by surface functionalization of heptylamine using a novel combined plasma polymerization mode. J Biomed Mater Res A. 2011;97(2):127-34.

41. Hichem S, Abdelaziz S, Latifa C, Kais R, Mohamed A, Jamel EB, et al. In vitro and in vivo antioxidant properties of Tunisian carob (Ceratonia siliqua L.). J Med Food Res. 2013;7:85-90.

42. Rodrigo R, Bosco C. Oxidative stress and protective effects of polyphenols: comparative studies in human and rodent kidney. A review. Comp Biochem Physiol C Toxicol Pharmacol. 2006;142:317-27.

43. Awaad AS, Al-Jaber NA, Moses JE, El-Meligy RM, Zain ME. Antiulcerogenic Activities of the Extracts and Isolated Flavonoids of Euphorbia cuneata Vahl. Phytother Res. 2013;27(1):126-30.

44. Bode C, Bode JC. Alcohol's Role in Gastrointestinal Tract Disorders. Alcohol Res Health. 1997;21:76-83.

45. Soojin P, Ki-baik H, Tae-young OH, Joo-hyun Jin BS, Ryowon C. Preventive Effect of the Flavonoid, Wogonin, Against Ethanol-Induced Gastric Mucosal Damage in Rats. Digest Dis Sci. 2004;49:384-94.

46. Park JH, Jang KJ, Kim CH, Kim JH, Kim YK, Yoon HM. Ganoderma Lucidum Pharmacopuncture for Teating Ethanol-induced Chronic Gastric Ulcers in Rats. Aust J Pharm. 2015;18:72-8.

47. Park JH, Jang KJ, Kim CH, Kim JH, Kim YK, Yoon HM. Ganoderma lucidum pharmacopuncture for teating ethanol-induced chronic gastric ulcers in rats. J Pharmacopuncture. 2015;18:72-8.
48. Pan JS, He SZ, Xu HZ, Zhan XJ, Yang XN, Xiao HM, et al. Oxidative stress disturbs energy metabolism of mitochondria in ethanol-induced gastric mucosa injury. World J Gastroenterol. 2008;14:5857-67.

49. Zhao M, Du YQ, Yuan $L$, Wang NN. Protective effect of puerarin on acute alcoholic liver injury. Am J Chin Med. 2010;38:241-9.

50. Calivarathan L, Laura EN, Thomas MM. Chronic ethanol ingestion induces oxidative kidney injury through taurine-inhibitable inflammation. Free Radical Bio Med. 2014;69:403-16.

51. Kannan M, Wang L, Kang YJ. Myocardial oxidative stress and toxicity induced by acute ethanol exposure in mice. Exp Biol Med (Maywood). 2004;229:553-9.

52. Haorah J, Knipe B, Leibhart J, Ghorpade A, Persidsky Y. Alcohol-induced oxidative stress in brain endothelial cells causes blood-brain barrier dysfunction. J Leukoc Biol. 2005;78:1223-32.

53. Zima T, Kalousov'a M. Oxidative stress and signal transduction pathways in alcoholic liver disease. Alcoholism: Clin Exp Res. 2005;29:110S-5S.

54. Sairam K, Rao CV, Dora BM, Agrawal VK, Goel RK. Antiulcerogenic activity of methanolic extract of Emblica officinalis. J Ethnopharmacol. 2002:82:1-9.

55. Kumazawa S, Taniguchi M, Suzuki Y, Shimura M, Kwon MS, Nakayama T. Antioxidant activity of polyphenols in carob pods. J Agric Food Chem. 2002:50:373-7.

56. Chen ZT, Chu HL, Chyau CC, Chu CC, Duh PD. Protective effects of sweet orange (Citrus sinensis) peel and their bioactive compounds on oxidative stress. Food Chem. 2012;135:2119-212.

57. Abd El-aal HA and Halaweish FT. Food preservative activity of phenolic compounds in orange peel extracts (Citrus sinensis L.). Lucrari Stiintifice. 2015:53:233-40.Seria Zootehnie.

58. Kogiannou DAA, Kalogeropoulos N, Kefalas P, Polissiou MG, Kaliora AC. Herbal infusions; their phenolic profile, antioxidant and anti-inflammatory effects in HT29 and PC3 cells. Food Chem Toxicol. 2013;61:152-9.

59. Szabo S. Role of sulfhydryls and early vascular lesions in gastric mucosal injury. Acta Physiol Hung. 1984;64:203-14.

60. Szabo S, Vattay P. Experimental gastric and duodenal ulcers. Advances in pathogenesis. Gastroenterol. Clin. North Am. 1990;19:67-85.

61. Davidson SM, Duchen MR. Calcium microdomains and oxidative stress. Cell Calcium. 2006:40:561-74

62. Ermak G, Davies KJA. Calcium and oxidative stress: from cell signaling to cell death. Mol Immunol. 2002;38:713-21.

63. Li YM, Li ZS, Zhou XP, Xie XF, Zhan XB. Effect of acid inhibitor on the function and ultra structure of gastric parietal cells in rats under stress. Jiefanjun Yixue Zazhi. 2002;27:1078-80.

64. Nobushi Y, Uchikura K. Selective detection of hydroxyl radical scavenging capacity based on electrogenerated chemiluminescence detection using tris(2,2' - bipyridine) ruthenium(III) by flow injection analysis. Chem Pharm Bull. 2010;58:117-20.

65. Jomova K, Valko M. Advances in metal-induced oxidative stress and human disease. Toxicology. 2011;283:65-87.

\section{Submit your next manuscript to BioMed Central and we will help you at every step:}

- We accept pre-submission inquiries

- Our selector tool helps you to find the most relevant journal

- We provide round the clock customer support

- Convenient online submission

- Thorough peer review

- Inclusion in PubMed and all major indexing services

- Maximum visibility for your research

Submit your manuscript at www.biomedcentral.com/submit
) Biomed Central 